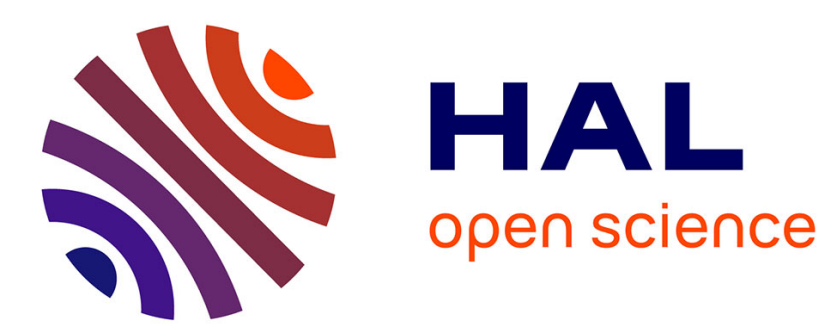

\title{
Optical Properties of CVD-Deposited Dielectric Films for Microelectronic Devices
}

\author{
A. Sassella, A. Borghesi, S. Rojas, L. Zanotti
}

\section{To cite this version:}

A. Sassella, A. Borghesi, S. Rojas, L. Zanotti. Optical Properties of CVD-Deposited Dielectric Films for Microelectronic Devices. Journal de Physique IV Proceedings, 1995, 05 (C5), pp.C5-843-C5-859. 10.1051/jphyscol:19955100 . jpa-00253767

\section{HAL Id: jpa-00253767 https://hal.science/jpa-00253767}

Submitted on 1 Jan 1995

HAL is a multi-disciplinary open access archive for the deposit and dissemination of scientific research documents, whether they are published or not. The documents may come from teaching and research institutions in France or abroad, or from public or private research centers.
L'archive ouverte pluridisciplinaire HAL, est destinée au dépôt et à la diffusion de documents scientifiques de niveau recherche, publiés ou non, émanant des établissements d'enseignement et de recherche français ou étrangers, des laboratoires publics ou privés. 


\title{
Optical Properties of CVD-Deposited Dielectric Films for Microelectronic Devices
}

\author{
A. Sassella, A. Borghesi*, S. Rojas** and L. Zanotti** \\ Dipartimento di Fisica "A. Volta", Università degli Studi di Pavia, via Bassi 6, 27I00 Pavia, Italy \\ * Dipartimento di Fisica, Università degli Studi di Modena, via Campi 213a, 41100 Modena, Italy \\ ** SGS-Thomson Microelectronics, via Olivetti 2, 20041 Agrate B. (MI), Italy
}

\begin{abstract}
Optical characterization of dielectric films used in integrated circuit device manufacturing can give information on their optical behavior as well as on their structural properties and composition. The results obtained on several undoped and doped silicon oxides, silicon oxynitrides, and silicon nitrides usually employed for microelectronic applications both in the ultraviolet-visible and infrared spectral ranges are illustrated.
\end{abstract}

\section{INTRODUCTION}

Silicon based dielectric films deposited by chemical vapor deposition (CVD) techniques are widely used in both very and ultra large scale integration (VLSI and ULSI) technology for integrated circuit device manufacturing. Among the large variety of dielectric materials that can be produced with CVD techniques, those concerning with this work are undoped silicon glass $\mathrm{SiO}_{2}$ (USG), phosphosilicate and borophosphosilicate glass (PSG and BPSG), silicon oxynitride and nitride films.

USG films deposited by plasma enhanced CVD (PECVD)[1] are principally used as intermetal insulation in multilevel interconnection devices and for final passivation stacked with PSG or oxynitride films. The main film properties required for this application are:

i) Deposition process temperature around or below $420{ }^{\circ} \mathrm{C}$ and compatible with metal layers;

ii) low dielectric constant $(\leq 4.1)$ to avoid parasitic capacitive and "cross-talking" effects;

iii) good electrical intermetal insulation;

iv) low compressive stress;

v) good film conformality.

Furthermore, $\mathrm{SiO}_{2}$ films deposited by low pressure CVD (LPCVD) based on a tetraethylorthosilicate (TEOS) liquid source are employed as protective diffusion masks under the intermediate BPSG films or for the formation of sidewall spacers.

Doped silicon glass films (i.e., PSG and BPSG) are mainly used as intermediate layers between overlying metallization and underlying polysilicon levels. The main characteristics required for this application are:

i) Conformal step coverage on micron and submicron structures;

ii) effective protection against alkali ions $\left(\mathrm{Na}^{+}, \mathrm{K}^{+}\right.$, etc.) that can lead to non reliable device performances;

iii) low temperature $\left(<950^{\circ} \mathrm{C}\right)$ reflow under standard furnace annealing for $1.0 \mu \mathrm{m}$ technology devices;

iv) complete film planarization for $0.5 \mu \mathrm{m}$ technology devices after rapid thermal annealing (RTA) for few seconds at about $1050{ }^{\circ} \mathrm{C}$;

v) good electrical insulation between metal and polysilicon layers. 
PSG films with a phosphorus content in the range $7 \div 8$ weight per cent (wt \%) and an annealing temperature of over $950^{\circ} \mathrm{C}$ are used for this application in device technology down to $1.0 \mu \mathrm{m}$. The increase of phosphorus in the film over $8 \mathrm{wt} \%$ leads to non reliable film properties.[2] PSG films used for this application are mainly deposited by a.tmospheric pressure CVD (APCVD).[3] To guarantee a lower reflow temperature $\left(<950^{\circ} \mathrm{C}\right)$ of intermediate layers, compatibile with shallow junction formation and necessary for device manufacturing of technology of $1.0 \mu \mathrm{m}$ and below, BPSG films replace PSG ones, the addition of boron producing a reduction of the reflow temperature. Typical doping concentrations in these films are in the range of $2 \div 3 \mathrm{wt} \%$ boron and $6 \div 8 \mathrm{wt} \%$ phosphorus.

PECVD silicon oxynitride films are mainly used for final passivation of devices assembled in plastic package, such as one time programmable, flash, and electrically erasable programmable read only memories. In particular, these films find a large use in the manufacturing of nonvolatile memory devices, due to their good cracking and moisture resistance, low compressive and easily controllable stress, and ultraviolet-visible (UV-vis) transparency for memory cell erasing. Oxynitride layers are often employed in combination with PSG films $(2 \div 4$ wt \% P) or USG and in many cases this stack is finished with a thick (some micrometers) polyimide buffer coating.

PECVD silicon nitride film characteristics match the requirements of a good final passivation very well. In fact, silicon nitride films provide better performances than oxynitride films (excepted UV-vis transparency) and, moreover, they give an efficient barrier against alkali ions and a conformal step coverage. In the last few years PECVD technique evolution has led to an easy stress control of such films and to the deposition of a silicon nitride that is UV-transmissive and has a low (about 1.9 at $632 \mathrm{~nm}$ wavelength) refractive index.

Regarding the techniques used for dielectric film deposition, the PECVD is largely adopted for intermetal and final passivation applications. Different models of plasma deposition systems, single chamber or batch, are commercially available; the features of new generation PECVD systems include single wafer processing, low particle contamination, sub-half micron complete gap filling capability, plasma-damage free processes, high density plasma generation, etc. APCVD technique is still widely used for the deposition of undoped oxides and doped intermediate ones like PSG and BPSG (both based on silane or TEOS silicon source). An important application of LPCVD technique concerns the deposition of high quality oxide films based on TEOS liquid source chemistry.

The aim of this work is to provide an overview of the optical properties of undoped and doped silicon glass, silicon oxynitride, and nitride films in the UV-vis and in the infrared (IR) spectral ranges. In Sec. 2 the properties that can be obtained by means of the optical characterization of CVD dielectric films in the two spectral ranges are illustrated. On this basis, in Sec. 3 the properties of the different films usually employed for microelectronic device manufacturing, i.e. undoped and doped silicon oxide, silicon oxynitride, and silicon nitride, are reviewed. Finally, the most important results and conclusions are summarized in Sec. 4.

\section{OPTICAL ANALYSIS}

In the UV-vis spectral range, typically from 0.2 to $0.9 \mu \mathrm{m}$ wavelength, the study of the optical properties of amorphous dielectric materials is related to the detection of their absorption edge and the determination of their optical energy gap. These characteristics are particularly important for some of the films used in microelectronic device manufacturing, depending on the type of application required. For example, the insulation properties of silicon oxide or nitride films are often fundamental when those materials are used as intermetal layers and are directely connected with the optical energy gap. At the same time, the transmission properties of oxynitride and nitride films, particularly relevant for final passivation layers in erasable programmable read only memories (EPROM), are related to both the real and imaginary parts of the complex refractive index $\tilde{n}=n+i k$ of the material.

The optical function which is usually employed to describe UV-vis properties is the complex dielectric function $\tilde{\epsilon}(E)=\epsilon_{1}(E)+i \epsilon_{2}(E)$, where $E$ is the photon energy, related to the refractive index by $\sqrt{\tilde{\boldsymbol{\epsilon}}}=\tilde{\boldsymbol{n}}$. From the spectra of $\epsilon_{2}$ the value of the optical gap can be obtained by plotting $E \sqrt{\epsilon_{2}(E)}$ vs $E$ (Tauc plot) or, similarly, $\sqrt{\alpha(E)}$ vs $E$, where $\alpha=4 \pi k / \lambda$ is the absorption coefficient and $\lambda$ the wavelength. The intercept of the extrapolated linear part of the curve with the energy axis is defined as the optical energy gap (or Tauc gap). [4]

The experimental techniques usually employed to study the UV-vis properties are transmit- 
tance and reflectance ( $T$ and $R$, respectively) measurements and spectroscopic ellipsometry. The measurements of $\mathrm{T}$ and $\mathrm{R}$ over a certain spectral range can lead to the determination of the dielectric function $\tilde{\epsilon}(E)$ of the sample by means of the Kramers Kronig relations, [5] once the geometrical structure of the sample is known. When studying a dielectric film deposited on a substrate, for example, one has to know the film thickness as well as the substrate optical function $(\tilde{\boldsymbol{\epsilon}}$ or $\tilde{n})$ over the spectral range of interest. In some cases, information on the film thickness also comes from the $R$ spectrum, where interference fringes may appear, and depend on both the film thickness and refractive index $n$.

The use of spectroscopic ellipsometry as a characterization tool has grown rapidly in recent years and is becoming more and more important.[6] The ellipsometric data obtained from the measurements are the functions $\tan \psi$ and $\cos \Delta$, which are related to the optical properties of the sample through the Fresnel reflection coefficients $\tilde{r}_{p}$ and $\tilde{r}_{s}$ :

$$
\frac{\tilde{r}_{p}}{\tilde{r}_{s}}=\tan \psi \exp i \Delta
$$

From this equation information on the structural and optical properties of the sample can be obtained. The bare data need to be elaborated on the basis of tentative models for both the sample structure (bulk sample or multilayer, number of layers, surface and interface sharpness, etc.) and the optical properties of layers and substrate. Several methods are available to describe the $\tilde{\epsilon}$ function of dielectric films, [6] such as those based on the Bruggeman effective medium theory[7] or on different analytical models. $[8,9]$

Although rather sophisticated, the very high sensitivity and reliability of spectroscopic ellipsometry have led researchers to prefer it to other optical techniques and, in particular, to singlewavelength ellipsometry, which can only provide one $n$ value (usually at $632.8 \mathrm{~nm}$ wavelength) and the film thickness. Indeed, different material compositions can result in the same $n$ value, and different refractive index-thickness pairs can correspond to the same $\tan \psi$ and $\cos \Delta$ data. Spectroscopic measurements in most cases permit these problems to be avoided. Nevertheless, it is important to underline that even a single $n$ value can be useful when comparing properties of different materials with nearly the same composition and structure. For example, in the case of $\mathrm{SiO}_{2}$ films grown with different techniques $n$ increases with density and with oxygen deficiency.[10]

Besides the material composition and structure, several factors affect the optical properties of dielectric films. These include the impurity type and content, the deposition technique used, and the thermal treatments they received, if any. As a typical example, in the dielectric films deposited by CVD, hydrogen atoms are often present as impurities (up to $10^{21}$ atoms $/ \mathrm{cm}^{3}$ ) and they may have an influence on the optical behavior of these films. The optical characterization in the IR range, usually performed in the medium IR from 5000 to $400 \mathrm{~cm}^{-1}$, provides information on the chemical bonds present in the films, on their composition and structural order. The spectral position of the absorption bands in the IR spectrum corresponds to the characteristic frequency of the bond giving rise to absorption, their intensity to the number of such bonds, and their width to the spread of the frequency value, i.e. to the structural order of the material. The study of these spectroscopic parameters can lead to a deep comprehension of the material properties and behavior under different conditions. For example, after annealing the characteristic IR absorption bands related to $\mathrm{Si}-\mathrm{O}$ bonds in silicon oxide usually appear narrower and more intense, indicating a reordering of the amorphous structure of the material. On the other hand, the intensity of the bands related to the presence of $\mathrm{Si}-\mathrm{H}$ bonds or $\mathrm{OH}$ groups, often present in several Si-based CVD films, strongly decreases after sample annealing, indicating a decrease of hydrogen atoms and $\mathrm{OH}$ groups in the film.

From the IR transmission spectrum a quantitative evaluation of the various bonds and impurities can also be performed (neglecting reflectance), after a calibration procedure on reference samples. Such a calibration has been carried out in the case of hydrogen atoms in silicon oxide and nitride, $[11,12]$ and recently extended to oxynitride, and conversion factors to obtain $\mathrm{H}$ concentration from the IR absorption bands related to $\mathrm{Si}-\mathrm{H}$ and $\mathrm{N}-\mathrm{H}$ bonds are available. The conversion factors to obtain $\mathrm{N}$ concentration from the absorption band due to $\mathrm{Si}-\mathrm{N}$ bonds[13] and $\mathrm{OH}$ concentration from the bands due to $\mathrm{Si}-\mathrm{OH}$ groups and $\mathrm{H}_{2} \mathrm{O}$ molecules are also available (at least for $\left.\mathrm{SiO}_{2}\right) \cdot[10,14]$ 
Following the procedure proposed in Ref. 12, the concentration of impurities, say hydrogen concentration $[\mathrm{H}]$, in atoms $/ \mathrm{cm}^{2}$ can be obtained from the area $A$ (in absorbance $\times \mathrm{cm}^{-1}$ ) of a related absorption band (for example, $\mathrm{Si}-\mathrm{H}$ or $\mathrm{N}-\mathrm{H}$ bands) considering:

$$
A \sigma^{-1}=[\mathrm{H}] \text {, }
$$

where $\sigma$ is the absorption cross-section (in $\mathrm{cm}^{2}$ ) of the particular bonds involved in the absorption process. To obtain the volume concentration of impurities in atoms $/ \mathrm{cm}^{3}$ the value $[\mathrm{H}]$ of Eq. (2) has to be normalized to the film thickness.

The experimental techniques adopted to study the IR properties of dielectric films are $T$ and $R$ measurements, usually performed with a Fourier transform spectrometer. For thin film characterization particular experimental techniques such as the attenuated total reflection measurements, [15] the IR absorption reflection spectroscopy, [16] and the surface mode excitation[17] are sometimes more suitable.

Ellipsometry has also been successfully applied in the IR spectral range,[18] but its use is still limited by the complex data treatment required, when considering that for most applications standard $\mathrm{T}$ measurements are fully satisfactory.

\section{RESULTS AND DISCUSSION}

The main properties of the dielectric films used in microelectronics coming from their optical characterization are here reviewed on the basis of the results obtained on the samples listed in Table I. For each compound some of its typical characteristics as well as its main applications in device manufacturing are reported.

Table I - Real refractive index $(n)$, density $(\rho)$, wet etch rate (ER), stress, and main applications of the films analyzed in this work.

\begin{tabular}{|c|c|c|c|c|c|}
\hline Film & $\begin{array}{c}n \\
(\text { at } 632.8 \mathrm{~nm})\end{array}$ & $\begin{array}{c}\rho \\
\left(\mathrm{g} / \mathrm{cm}^{3}\right)\end{array}$ & $\begin{array}{c}\mathrm{ER} \\
(\mathrm{nm} / \mathrm{min})\end{array}$ & $\begin{array}{c}\text { Stress } \\
\left(10^{9} \text { dyne } / \mathrm{cm}^{2}\right)\end{array}$ & Applications \\
\hline \multicolumn{6}{|l|}{ USG } \\
\hline LPCVD TEOS & $1.430-1.442$ & $2.11-2.15$ & $31.3^{a}$ & $-1 \div+0.5$ & \multirow{4}{*}{$\begin{array}{l}\text { sidewall spacer } \\
\text { diffusion barrier } \\
\text { intermetal } \\
\text { diffusion barrier } \\
\text { final passivation } \\
\text { intermetal }\end{array}$} \\
\hline PECVD TEOS & 1.448 & 2.12 & 69.6 & -0.23 & \\
\hline APCVD $\mathrm{SiH}_{4}$ & 1.440 & 2.07 & 102.3 & +1 & \\
\hline PECVD $\mathrm{SiH}_{4}$ & 1.475 & 2.19 & 103.5 & -0.75 & \\
\hline \multicolumn{6}{|l|}{ PSG } \\
\hline APCVD $\mathrm{SiH}_{4}$ & 1.450 & 2.10 & 374.4 & +1.3 & \multirow{3}{*}{$\begin{array}{l}\text { final passivation } \\
\text { intermediate } \\
\text { final passivation } \\
\text { final passivation }\end{array}$} \\
\hline PECVD $\mathrm{SiH}_{4}$ & 1.460 & 2.26 & 156.0 & +0.02 & \\
\hline PECVD TEOS & 1.452 & 2.15 & 255.9 & +0.3 & \\
\hline \multicolumn{6}{|l|}{ BPSG } \\
\hline APCVD $\mathrm{SiH}_{4}$ & 1.464 & 2.25 & $312.0^{b}$ & +0.25 & \multirow{3}{*}{$\begin{array}{l}\text { intermediate } \\
\text { intermediate } \\
\text { intermediate }\end{array}$} \\
\hline LPCVD TEOS & 1.464 & 2.20 & $180.0^{b}$ & -0.2 & \\
\hline LPCVD $\mathrm{SiH}_{4}$ & 1.464 & 2.20 & $625.0^{b}$ & -0.4 & \\
\hline oxynitride & 1.7 & 2.35 & - & -0.4 & final passivation \\
\hline nitride std & 2.0 & 2.44 & - & -1.1 & final passivation \\
\hline nitride UV & 1.89 & 2.56 & - & -1.1 & final passivation \\
\hline
\end{tabular}

a measured using a 1:40 HF solution

${ }^{b}$ measured using a 1:7 HF solution 
In the table the different films are labelled with the technique and the silicon source used during deposition. The wet etch rate is measured using a 1:10 HF solution in deionized water; the positive stress values refer to tensile stress, while the negative ones to compressive stress. Among the BPSG listed, that deposited by LPCVD from silane is not currently used in device manufacturing, but has been analyzed for comparison with the others.

\subsection{Undoped silicon oxide.}

Undoped silicon oxide films deposited by different techniques and used for several different applications were studied by means of optical analysis. The most interesting results on samples deposited by APCVD from silane ( $\left.\mathrm{SiH}_{4}\right)$, deposited by PECVD from $\mathrm{SiH}_{4}$ or from TEOS, and deposited by LPCVD from TEOS are here reviewed.[19,20] The process conditions used for the different depositions are reported in Table Il; for the films deposited by LPCVD different conditions were used and the table reports the ranges of the various parameters.

Table II - Deposition parameters used for the different undoped silicon oxide samples studied.

\begin{tabular}{lcccc}
\hline & $\begin{array}{c}\text { APCVD } \\
\mathrm{SiH}_{4}\end{array}$ & $\begin{array}{c}\text { PECVD } \\
\text { TEOS }\end{array}$ & $\begin{array}{c}\text { PECVD } \\
\mathrm{SiH}_{4}\end{array}$ & $\begin{array}{c}\text { LPCVD } \\
\text { TEOS }\end{array}$ \\
\hline Pressure (Torr) & 760 & 9 & 3 & $0.4-0.8$ \\
Temperature $\left({ }^{\circ} \mathrm{C}\right)$ & 420 & 390 & 400 & $650-745$ \\
TEOS $\left(\mathrm{sccm}^{a}\right)$ & - & $50^{b}$ & - & $3-5^{d}$ \\
$\mathrm{SiH}_{4}(\mathrm{sccm})$ & $85^{c}$ & - & 45 & - \\
$\mathrm{N}_{2} \mathrm{O}(\mathrm{sccm})$ & - & - & 1100 & - \\
$\mathrm{O}_{2}(\mathrm{sccm})$ & 260 & 470 & - & $50-200$ \\
\hline
\end{tabular}

a standard $\mathrm{cm}^{3} / \mathrm{min}$

${ }^{b}$ in $380 \mathrm{sccm} \mathrm{He}[1]$

c $15 \%$ volume in Ar

d measured through the TEOS line pressure (Torr)

Due to their applications (see Table I), these films have been studied mainly in the IR range, where information on impurities and characteristic bonds can be obtained; on the contrary, the UV-vis study has been limited to the determination of the real part $n$ of the refractive index at $632.8 \mathrm{~nm}$ wavelength, useful as a general characterization parameter. The films deposited by APCVD show $n=1.440$, while those deposited by PECVD from $\mathrm{SiH}_{4}$ have $n=1.472$, in any case very close to the thermal $\mathrm{SiO}_{2}$ refractive index. A higher $n$ value indicates that the amorphous network of the film is more disordered and the composition different from $\mathrm{SiO}_{2}$ stoichiometry; in particular, in the case of PECVD films it is well known that hydrogen impurities are often present.

The real part of refractive index of LPCVD $\mathrm{SiO}_{2}$ films deposited by TEOS varies as a function of the different conditions used. The variation of the deposition temperature in the range from 650 to $745^{\circ} \mathrm{C}$ seems to play a key role, leading to different $n$ values, from 1.428 to 1.446 . In this case, the close correlation observed between the refractive index and the density $\rho$ indicates that the variation of $n$ is mainly due to a different atomic arrangement in the structure of the different samples. In other words, here the Clausius-Mossotti relation:

$$
\rho=K \frac{n^{2}-1}{n^{2}+2}
$$

where $K$ is a constant evaluated from reference data, is fully satisfied.[19]

In the IR spectrum of USG films two absorption bands related to $\mathrm{OH}$ bonds are detectable, one at about $3450 \mathrm{~cm}^{-1}$ attributed to the stretching of $\mathrm{OH}$ in $\mathrm{H}_{2} \mathrm{O}$ molecules embedded in the film and one at about $3650 \mathrm{~cm}^{-1}$ attributed to $\mathrm{OH}$ bond stretching in Si-OH groups. The detection limit for $\mathrm{OH}$ bonds is rather high, i.e. about $0.1 \mathrm{wt} \%$. At about $2200 \mathrm{~cm}^{-1}$ the presence of $\mathrm{Si}-\mathrm{H}$ bonds can be detected and a concentration of such bonds evaluated from the area of the corresponding absorption bands. At lower wave numbers the three characteristic absorption bands 
related to Si-O bonds are detectable at about $1080 \mathrm{~cm}^{-1}, 810 \mathrm{~cm}^{-1}$, and $450 \mathrm{~cm}^{-1}$, attributed to $\mathrm{Si}-\mathrm{O}$ stretching mode, to $\mathrm{Si}-\mathrm{O}-\mathrm{Si}$ bending mode, and to $\mathrm{Si}-\mathrm{O}-\mathrm{Si}$ rocking mode, respectively.

The quantitative analysis carried out on the $\mathrm{OH}$-related absorption bands present in the spectra of the samples of Table II shows that the films deposited by APCVD contain up to one order of magnitude more $\mathrm{OH}$ bonds than those deposited by PECVD; moreover, TEOS-based films are richer in $\mathrm{OH}$ than silane-based ones, although they are both deposited by PECVD. Annealing at $430{ }^{\circ} \mathrm{C}$ in $\mathrm{N}_{2}$ for 15 min leads to only a slight reduction of $\mathrm{Si}-\mathrm{OH}$ content in both APCVD and PECVD films, while the $\mathrm{H}_{2} \mathrm{O}$-related absorption band is strongly reduced, as observed in Fig. 1 where the spectra of as-deposited and annealed undoped $\mathrm{SiO}_{2}$ films obtained by APCVD are shown. Silicon oxide films deposited by LPCVD show a different behavior: the intensity of both $\mathrm{OH}$-related absorption bands is reduced by annealing at $950^{\circ} \mathrm{C}$ in $\mathrm{N}_{2}$ for $15 \mathrm{~min}$ to below the IR detection limit. As an example, in Fig. 2 the IR spectra of as-deposited and annealed films deposited by LPCVD at $650^{\circ} \mathrm{C}$ are shown. In the whole range of deposition temperatures used (see Table II) the concentration of $\mathrm{OH}$ bonds in all the as-deposited films is almost the same.

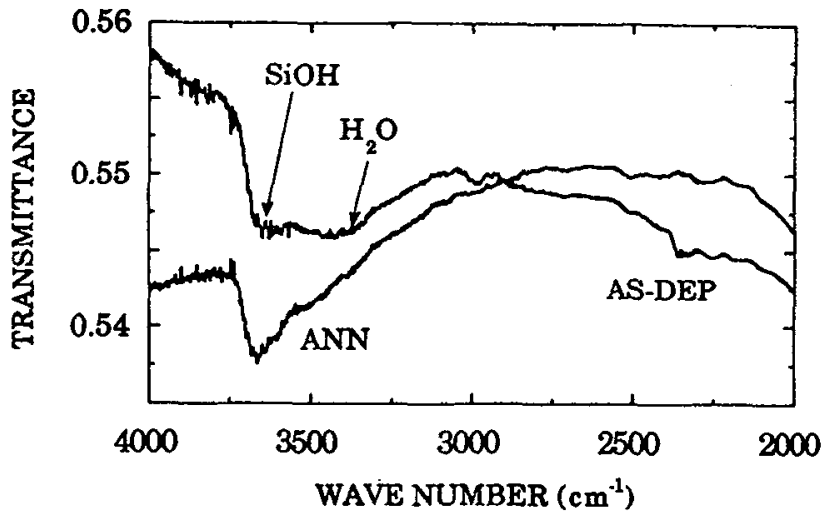

Fig. 1 Transmittance spectra of the USG film as-deposited by APCVD and annealed.

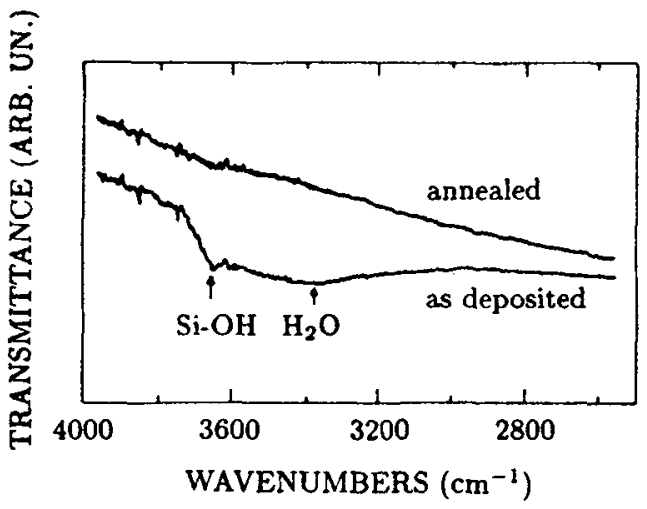

Fig. 2 Transmittance spectra of the USG film as-deposited by LPCVD at $650^{\circ} \mathrm{C}$ and annealed.

The main absorption band of $\mathrm{SiO}_{2}$, i.e. that due to the $\mathrm{Si}-\mathrm{O}$ stretching mode, is very similar in the spectra of APCVD and TEOS-based PECVD films, showing the same spectral position and full-width at half maximum (FWHM), i.e. $1078 \mathrm{~cm}^{-1}$ and $210 \mathrm{~cm}^{-1}$, respectively. The same band is observed at $1066 \mathrm{~cm}^{-1}$ with a FWHM of $220 \mathrm{~cm}^{-1}$ in the spectrum of $\mathrm{SiH}_{4}$-based USG 
films deposited by PECVD and, therefore, they are deduced to be more disordered and slightly apart from $\mathrm{SiO}_{2}$ stoichiometry. The spectra of these three films are shown in Fig. 3. The same absorption band in the IR spectra of the films deposited by LPCVD from TEOS is at $1068 \mathrm{~cm}^{-1}$ with a FWHM of $79 \mathrm{~cm}^{-1}$, independently of the deposition temperature used. After the annealing the frequency of this band increases to about $1072 \mathrm{~cm}^{-1}$ for all films, while its FWHM remains almost unchanged. Although the spectral position detected is rather far from the $1078 \mathrm{~cm}^{-1}$ of thermal $\mathrm{SiO}_{2}$ (usually considered as a reference silicon oxide), the low FWHM of the band and the independence of all parameters with respect to the deposition temperature lead to the belief that the films deposited by LPCVD are stoichiometric $\mathrm{SiO}_{2}$ with a porous structure. A densification may be obtained by annealing, as deduced from the increase of the spectral position of the Si-O stretching band. The study of the rocking mode of Si-O-Si groups at about $450 \mathrm{~cm}^{-1}$ confirms the trends reported above for all films.

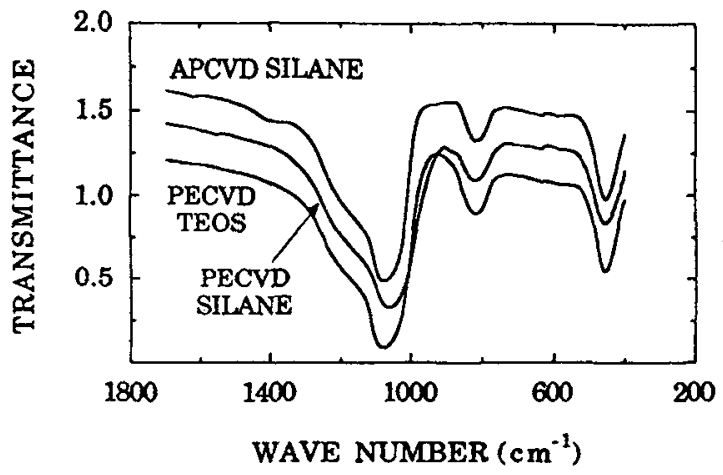

Fig. 3 Transmittance spectra of three as-deposited USG films obtained by PECVD from TEOS, by PECVD from $\mathrm{SiH}_{4}$ (shifted by 0.25 ), and by APCVD (shifted by 0.5 ).

\subsection{Doped silicon oxide.}

The $\mathrm{SiO}_{2}$ films doped with $\mathrm{P}$ and $\mathrm{B}$ used in microelectronics are usually deposited by a CVD technique. The main information that can be obtained on these materials by means of optical characterization is here illustrated for PSG films deposited on silicon substrates by APCVD and PECVD from different sources, and for BPSG films deposited by APCVD, and by LPCVD from different sources.[20,21] Silicon sources are $\mathrm{SiH}_{4}$ or TEOS, while for the dopants $\mathrm{PH}_{3}$ and $\mathrm{B}_{2} \mathrm{H}_{6}$ gases or trimethylphosphite (TMP) and trimethylborate (TMB) liquid sources are employed. Table III reports the deposition parameters used to obtain the different samples.

The refractive index of PSG films shows the same behavior as that of undoped oxide, i.e. it is slightly higher for PECVD films than for APCVD ones. Its value, about 1.464 for all as-deposited BPSG samples, increases slightly after annealing (1.475) due to film densification (both density and etch rate data support this interpretation).

In the IR range the spectra of $\mathrm{PSG}$ films show the $\mathrm{OH}$-related absorption bands detected also in the USG spectra. Annealing at $430^{\circ} \mathrm{C}$ in $\mathrm{N}_{2}$ for 15 min reduces the $\mathrm{OH}$ content in $\mathrm{SiH}_{4}$-based $\mathrm{P}$-doped films more than in the analogous undoped films, while it is ineffective on TEOS-based PSG films. Deconvolution of the IR spectra from 4000 to $2800 \mathrm{~cm}^{-1}$ reveals that a third OH band, related to more strongly bonded $\mathrm{Si}-\mathrm{OH}$ groups which probably share the $\mathrm{Si}$ atom, is present at about $3537 \mathrm{~cm}^{-1}$. [10,20] The PSG samples deposited by APCVD are the only ones which contain $\mathrm{Si}-\mathrm{H}$ bonds, evaluated from the $2200 \mathrm{~cm}^{-1}$ absorption band to be about $4 \times 10^{20} \mathrm{~cm}^{-3}$.

The IR transmission spectra of $\mathrm{P}$-doped $\mathrm{SiO}_{2}$ films in the low wave number range where the main absorption bands are detectable are reported in Fig. 4. The position and FWHM of the Si-O stretching band are the same for the three different films, i.e. $1089 \mathrm{~cm}^{-1}$ and about $210 \mathrm{~cm}^{-1}$, respectively. These data suggest that PSG are highly disordered (high FWHM) $\mathrm{SiO}_{2}$ stoichiometric oxides. 
Table III - Deposition parameters used for the different doped silicon oxide samples (PSG and BPSG) studied.

\begin{tabular}{|c|c|c|c|c|c|c|}
\hline & $\begin{array}{l}\text { PSG } \\
\mathrm{APCVD} \\
\mathrm{SiH}_{4}\end{array}$ & $\begin{array}{l}\text { PSG } \\
\text { PECVD } \\
\text { TEOS }\end{array}$ & $\begin{array}{l}\mathrm{PSG} \\
\mathrm{PECVD} \\
\mathrm{SiH}_{4}\end{array}$ & $\begin{array}{l}\text { BPSG } \\
\text { APCVD } \\
\mathrm{SiH}_{4}\end{array}$ & $\begin{array}{l}\text { BPSG } \\
\text { LPCVD } \\
\mathrm{SiH}_{4}\end{array}$ & $\begin{array}{l}\text { BPSG } \\
\text { LPCVD } \\
\text { TEOS }\end{array}$ \\
\hline $\begin{array}{l}\mathrm{P} \text { (Torr) } \\
\mathrm{T}\left({ }^{\circ} \mathrm{C}\right) \\
\text { TEOS }(\mathrm{sccm}) \\
\text { TMB }(\mathrm{sccm}) \\
\text { TMP (sccm) } \\
\mathrm{SiH}_{4}(\mathrm{sccm}) \\
\mathrm{PH}_{3}(\mathrm{sccm}) \\
\mathrm{B}_{2} \mathrm{H}_{6}(\mathrm{sccm}) \\
\mathrm{N}_{2} \mathrm{O}(\mathrm{sccm})\end{array}$ & $\begin{array}{r}277^{a} \\
87^{b}\end{array}$ & $\begin{array}{c}9 \\
390 \\
50^{c} \\
3\end{array}$ & $\begin{array}{c}90 \\
300^{b} \\
2000\end{array}$ & $\begin{array}{l}323 \\
406 \\
343\end{array}$ & $\begin{array}{c}110^{d} \\
95^{e}\end{array}$ & $\begin{array}{c}0.4 \\
680 \\
1800^{f} \\
590^{f}\end{array}$ \\
\hline $\mathrm{O}_{2}(\mathrm{sccm})$ & 1020 & 470 & & 4060 & 270 & 150 \\
\hline
\end{tabular}

a $15 \%$ volume in $\mathrm{Ar}$

${ }^{6} 3 \%$ volume in $\mathrm{Ar}$

$c$ in $380 \mathrm{sccm}$ He

d $20 \%$ volume in $\mathrm{SiH}_{4}$

e $40 \%$ volume in $\mathrm{SiH}_{4}$

$f$ measured through TEOS and TMB line pressures (mTorr)

At about $1320 \mathrm{~cm}^{-1}$ absorption of $\mathrm{P}=\mathrm{O}$ bonds occurs and its intensity depends directly on the $\mathrm{P}$ content in the sample (from 3.5 to $4.5 \mathrm{wt} \%$ in the samples of Table III), being therefore measurable. After the annealing this band increases because of the loss of $\mathrm{H}_{2} \mathrm{O}$ molecules as $\mathrm{P}=0$ bonds modify their surroundings in the presence of such molecules following the scheme:

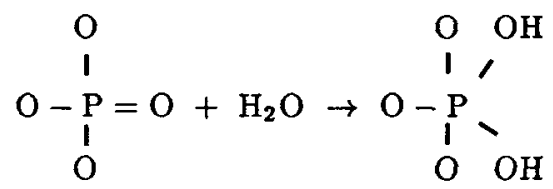

therefore becoming IR inactive.[21]

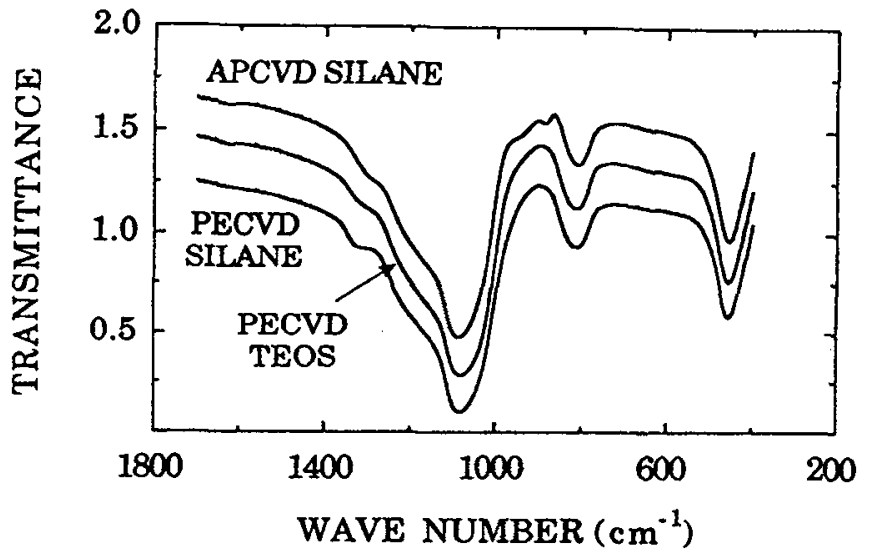

Fig. 4 Transmittance spectra of PSG films as-deposited by the different CVD techniques. 
Among BPSG films, those deposited by LPCVD from silane are the only ones with a detectable $\mathrm{OH}$ content, probably related to the incomplete oxidation of the reactants during deposition, which leads to hygroscopic films. In the range from 2000 to $400 \mathrm{~cm}^{-1}$ the spectra of BPSG films show several absorption bands, as observed in Fig. 5. The Si-O stretching band is at about 1090 $\mathrm{cm}^{-1}$, with a lower FWHM for the LPCVD films deposited from TEOS; therefore, these films are deduced to possess a more ordered network, possibly due to the low $\mathrm{P}$ content and high deposition temperature. At about $1390 \mathrm{~cm}^{-1}$ and $1320 \mathrm{~cm}^{-1}$, the stretching of $\mathrm{B}-\mathrm{O}$ and $\mathrm{P}=\mathrm{O}$ bonds respectively gives rise to absorption, while at about $920 \mathrm{~cm}^{-1}$ absorption is related to B-O-Si groups.

After annealing (RTA at $1050^{\circ} \mathrm{C}$ or furnace annealing at $920^{\circ} \mathrm{C}$ in different ambients) the intensity of the $\mathrm{P}=\mathrm{O}$ absorption band is enhanced, while that of $\mathrm{OH}$-related band is reduced. These two effects are correlated, as already explained, and are particularly evident in the spectra of BPSG films deposited by LPCVD from $\mathrm{SiH}_{4}$ : in the spectrum of as-deposited samples no $\mathrm{P}=\mathrm{O}$ absorption is detectable, while in those collected after sample annealing it clearly shows up. Finally, film densification and reordering are other effects of annealing, common to all films.

Among the B- and P-doped oxides analyzed, those deposited by LPCVD from TEOS are the most stoichiometric and stable, as deduced from the high wave number of $\mathrm{Si}-\mathrm{O}$ stretching band and very slight annealing-induced effects.

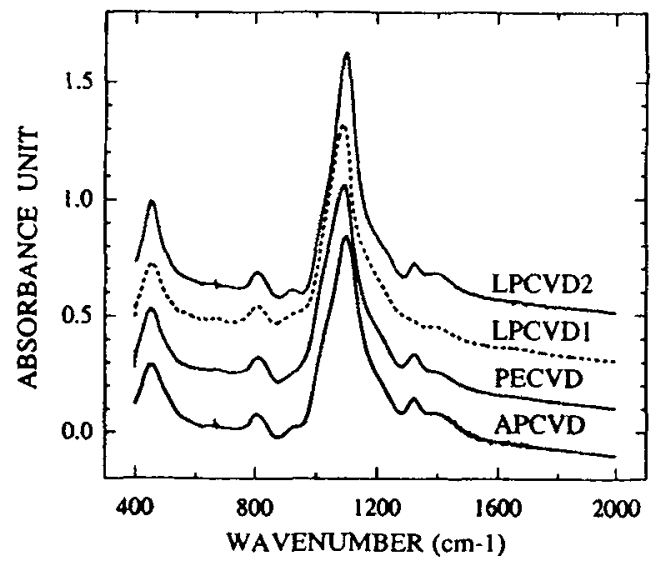

Fig. 5 Absorbance spectra of as-deposited BPSG films obtained by the different techniques.

\subsection{Silicon oxynitride and nitride.}

As clearly appears in the introduction, silicon oxynitrides (with the general formula $\mathrm{SiO}_{x} \mathrm{~N}_{y}$ ) have become more and more interesting in recent years for several applications. CVD techniques are widely used to deposit these materials, giving the possibility of obtaining films with controlled composition. The interest in such dielectric compounds has led to the publication of a lot of research papers regarding both deposition and characterization, as well as theoretical modelling.[22]

To give an overview of the main optical properties of silicon oxynitride and nitride, the study of a series of $0.25 \mu \mathrm{m}$ thick films with varying composition and hydrogen content deposited by PECVD is illustrated. [23-26] The fiuxes of the reactants used in the deposition of those samples are listed in Table IV. Sample 4 is the silicon oxynitride used in the applications, while samples 7 and 8 respectively are the UV-transparent and standard silicon nitride (see Table I).

The oxynitride samples (samples 1 to 6 ) have been studied in great detail in both the UVvis and IR spectral ranges, but for a full characterization further data are needed. In particular, the stoichiometry indices $x, y$, and $z$ of the general formula of hydrogen-rich silicon oxynitride $\mathrm{SiO}_{x} \mathrm{~N}_{y} \mathrm{H}_{z}$ were measured by means of Rutherford back scattering, nuclear reaction analysis, and elastic recoil detection; the film density is derived from weight and volume measurements. The data obtained are listed in Table $\mathrm{V}$. The table shows that sample 1 is very close to $\mathrm{SiO}_{2}$, while samples 7 and 8 are close to $\mathrm{Si}_{3} \mathrm{~N}_{4}$ (corresponding to $x=0$ and $y=1.33$ ). 
Table IV - Fluxes of the reactants (in sccm) used to obtain silicon oxynitride and nitride films by PECVD; deposition temperature is $400^{\circ} \mathrm{C}$ for all samples.

\begin{tabular}{lcccc}
\hline Sample & $\mathrm{SiH}_{4}$ & $\mathrm{NH}_{3}$ & $\mathrm{~N}_{2} \mathrm{O}$ & $\mathrm{N}_{2}$ \\
\hline 1 & 45 & - & 1100 & - \\
2 & 110 & - & 100 & 1500 \\
3 & 110 & 75 & 100 & 1500 \\
4 & 110 & 93 & 73 & 2500 \\
5 & 110 & 93 & 50 & 2500 \\
6 & 110 & 93 & 25 & 2500 \\
7 & 145 & 60 & - & 2000 \\
8 & 55 & 55 & - & 2500
\end{tabular}

Table V - Composition indices $x, y$, and $z$ and density $\rho$ (in $\mathrm{g} / \mathrm{cm}^{3}$ ) of the silicon oxynitride films deposited by PECVD.

\begin{tabular}{lllll}
\hline Sample & $x$ & $y$ & $z$ & $\rho$ \\
\hline 1 & 1.82 & 0.13 & 0.14 & 2.20 \\
2 & 1.16 & 0.46 & 0.26 & 2.29 \\
3 & 0.90 & 0.85 & 0.52 & 2.30 \\
4 & 0.50 & 0.85 & 0.48 & 2.37 \\
5 & 0.26 & 0.67 & 0.37 & 2.39 \\
6 & 0.25 & 1.27 & 0.68 & 2.45 \\
7 & 0.02 & 1.31 & 0.51 & 2.56 \\
8 & 0.02 & 1.02 & 0.50 & 2.44 \\
\hline
\end{tabular}

The UV-vis properties of silicon oxynitride and nitride are particularly relevant when those compounds are used as final passivation layers for EPROM cells which have to be cancelled by UV irradiation (the spectrum of the lamps usually employed is from about 0.2 to $0.3 \mu \mathrm{m}$ wavelength). The study of optical absorption and reflection in this spectral range has been performed by means of ellipsometry and reflectance measurements.

Before illustrating the results, it is worth mentioning that the interpretation of ellipsometric data requires a preliminary analysis of the most adequate models for the sample structure and optical behavior. [6] In the case of silicon oxynitride this analysis was carried out[23] considering, besides the direct calculation of the real and imaginary parts of the complex refractive index $\tilde{n}$ from Eq. 1, the Bruggeman effective medium[7] and the Sellmeier analytical model.[8] Direct calculation can give good $n$ results, but the $k$ spectra are completely unreliable because the spectral range of ellipsometry data is precisely where $k$ has a very low value, but higher than zero (of the order of 0.01). The use of the Bruggeman model considering. $\mathrm{SiO}_{2}$ and $\mathrm{Si}_{3} \mathrm{~N}_{4}$ as two components for $\mathrm{SiO}_{x} \mathrm{~N}_{y} \mathrm{H}_{z}$ leads to a good fit of experimental data, in particular when the samples are considered as two layers with different composition deposited on the silicon substrate. Regarding this method for data treatment, two remarks are necessary. First, the Bruggeman model is adequate to the PECVD oxynitride samples only as a way to obtain a good fit of ellipsometric spectra, but it does not suggest that these samples are physically a mixture of two phases (namely, $\mathrm{SiO}_{2}$ and $\mathrm{Si}_{3} \mathrm{~N}_{4}$ ). From IR data (see below) it appears clearly that the samples are homogeneous, i.e. their structure is a completely random distribution of $\mathrm{Si}-\mathrm{O}$ and $\mathrm{Si}-\mathrm{N}$ bonds, which can be described in the framework of the random bonding model.[27] Second, the two-layer structure is probably a good physical model for PECVD films, because it improves the data fit and it is in agreement with other findings reported in the literature. [28-30]

The spectra obtained from ellipsometry on the basis of this analysis (Bruggeman model and two-layer structure) are shown in Fig. 6 for the silicon oxynitride samples. Both $n$ and $k$ values increases in the whole spectral range as the oxygen content in the sample decreases (i.e. from sample 1 to sample 6 ). The same trend and nearly the same absolute values for $n$ are found on the 
basis of the Sellmeier model, which does not give satisfactory results for the extinction coefficient $k$.

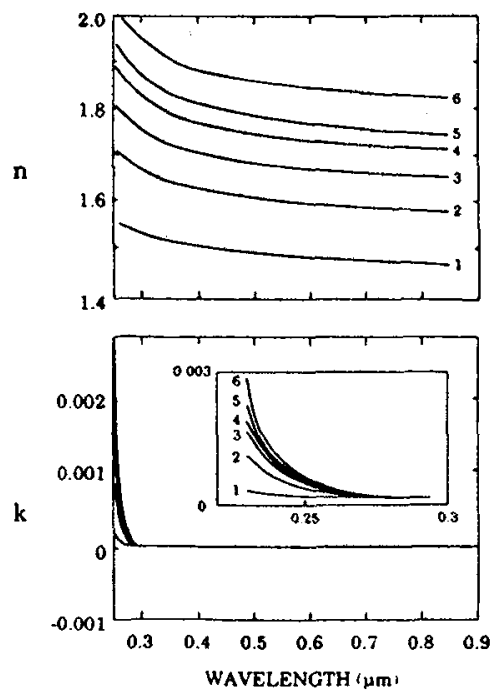

Fig. 6 Real and imaginary parts $n$ and $k$ of the complex refractive index of silicon oxynitride.

To evaluate the optical energy gap of the different oxynitride samples the Tauc plot as obtained after extrapolating the $k$ spectra derived from ellipsometry up to $10.5 \mathrm{eV}$ is considered.[24] In the strong absorption region $\sqrt{\alpha}$ versus $\mathrm{E}$ shows a linear behavior and the optical gap $\mathrm{E}_{g}$ can be obtained. Figure 7 is the Tauc plot for the samples from 1 to 6 ; the values of $E_{g}$ range from about $9.3 \mathrm{eV}$ to $7.7 \mathrm{eV}$, scaling down with oxygen content in the sample. For comparison, it is useful to note that literature $\mathrm{SiO}_{2}$ and $\mathrm{Si}_{3} \mathrm{~N}_{4}$ have an energy gap of about $9.4 \mathrm{eV}$ and $5.3 \mathrm{eV}$, respectively. The gap widening as a function of oxygen content has been related to the shift of the bottom of the conduction band to higher energy.[31-34] It is interesting to note that several authors found that $\mathrm{E}_{g}$ increases as a function of oxygen content; slowly in the O-rich samples and more rapidly in the $\mathrm{N}$-rich samples. [24.32,34]

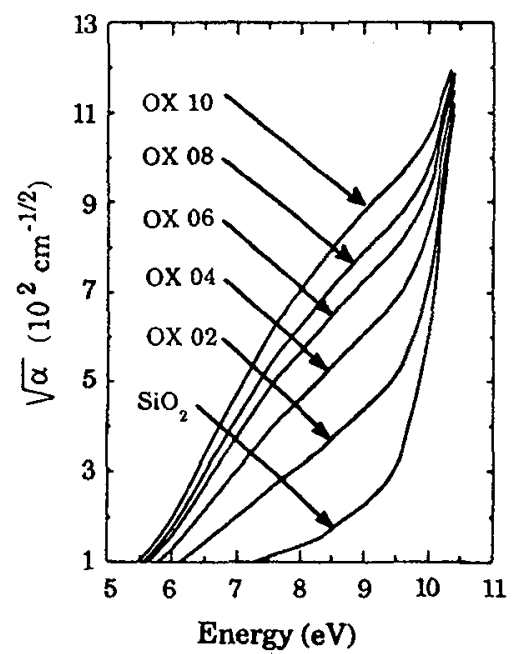

Fig. 7 Tauc plot for the silicon oxynitride samples. 
Reflectance measurements in the range from 0.19 to $0.70 \mu \mathrm{m}$ show[24] strong interference fringes, due to the superposition of light reflected by the air/film and film/substrate interfaces. At high energy the second interface contribution becomes negligible as the extinction coefficient of the film increases (samples with higher $\mathrm{N}$ content). The comparison of experimental reflectance spectra and reflectance spectra calculated using literature optical data for the silicon substrate and the ellipsometric data of Fig. 6 for the oxynitride films, leads to a very good agreement.

Recently, a model has been developed[35] to evaluate the dielectric function of hydrogenrich silicon oxynitride on the basis of the tetrahedron model, initially proposed for silicon oxide and nitride.[36,37] The short range order present in the amorphous network of several Si-based compounds (including silicon oxynitride) is the fundamental point. In particular, silicon oxynitride is considered to be a random arrangement of groups of five tetrahedrally coordinated atoms: a central silicon atom and four different atoms at the vertices of a regular tetrahedron. The presence and number in the sample of each different tetrahedral structure, i.e. with different vertex species, depends on the composition. For $\mathrm{H}$-rich silicon oxynitride the possible vertex species are $\mathrm{O}, \mathrm{N}$, $\mathrm{Si}, \mathrm{H}$, and $\mathrm{NH}$ groups, therefore 30 tetrahedra have to be considered (having excluded some less energetically favored atomic bonds).

For each tetrahedral unit $i$ a complex dielectric function $\tilde{\epsilon}_{i}$ is calculated by scaling the experimental dielectric function of a reference material (typically $\mathrm{SiO}_{2}$ or $\mathrm{Si}_{3} \mathrm{~N}_{4}$ ) both with respect to intensity and spectral position. The scaling coefficients are calculated according to the type of atoms and bonds present in the particular unit. Taking into account these structural units, from the composition of the sample, i.e. from the experimental indices $x, y$, and $z$ in the formula $\mathrm{SiO}_{x} \mathrm{~N}_{y} \mathrm{H}_{z}$ (see Table $\mathrm{V}$ ), the volume fraction $v_{i}$ occupied by each unit is evaluated and then used to calculate a weighted average of the different dielectric functions of the tetrahedra. Finally, the dielectric function $\tilde{\epsilon}$ of the silicon oxynitride is obtained from:

$$
\sum_{i=1}^{N} v_{i} \frac{\tilde{\epsilon}_{i}-\tilde{\epsilon}}{\tilde{\epsilon}_{i}+2 \tilde{\epsilon}}=0
$$

where $N$ is the total number of tetrahedral structures considered.

When studying real samples, [26] a volume fraction $v_{v}$ occupied by void and the corresponding dielectric function $\tilde{\boldsymbol{\epsilon}}=1+i 0$ have to be included in Eq. (4) to take into account the possible density deficiency with respect to the ideal compound with the same $x, y$, and $z$ values, i.e. a compound where all bonds are saturated and the atoms are closely packed. The volume fraction $v_{v}$ is evaluated by:

$$
v_{v}=1-\frac{\rho}{\rho_{t}}
$$

where $\rho$ and $\rho_{t}$ are the experimental and theoretical density values, respectively. Moreover, because two bond configurations are possible for hydrogen atoms, i.e. Si- $\mathrm{H}$ and $\mathrm{N}-\mathrm{H}$, they have to be taken into account separately. When $\mathrm{Si}-\mathrm{H}$ bonds are considered, the tetrahedral units with $\mathrm{H}$ vertex atoms are the ones adequate to the dielectric function modelling, while for $\mathrm{N}-\mathrm{H}$ bonds tetrahedra with $\mathrm{NH}$ vertex groups have to be included in the model; when both types of bonds are present in the sample under study the ratio $\mathrm{Si}-\mathrm{H} / \mathrm{N}-\mathrm{H}$ experimentally measured by means of IR spectroscopy is needed, and Eq.(4) can be successfully applied.

The extension of the tetrahedron model to silicon oxynitride has been tested[26] by comparing the results with experimental $n$ and $k$ spectra obtained from ellipsometry measurements. Figure 8 shows such a comparison performed for sample 1. The continuous lines are the results of the calculations based on the tetrahedron model, obtained considering the data of Table $\mathrm{V}$ and the experimental $\mathrm{Si}-\mathrm{H} / \mathrm{N}-\mathrm{H}$ ratio 0.006 . The dashed lines are the results of the same calculations obtained considering the maximum experimental error in the determination of composition indices $( \pm 10 \%)$ and density $( \pm 5 \%)$, the full circles are the ellipsometry results evaluated by means of the Bruggeman model considering a two-layer structure, and the open circles are the ellipsometry results obtained on the basis of the Sellmeier model. The agreement between calculated and experimental $n$ spectra is very good, although it is important to note that the experimental uncertainty on $x, y, z$, and $\rho$ leads to a strong difference in the calculated values. In other words, the model turns out to be much more sensitive to composition and density than the experimental techniques used to measure such parameters. Regarding the $k$ spectra, ellipsometry data are not completely 
reliable, due to the very low values of silicon oxynitride $k$ in the investigated spectral range. In addition, the model includes in the material as many $\mathrm{Si}-\mathrm{Si}$ bonds as necessary to saturate all bonds (this is one of the basic assumptions for the tetrahedron model), while in the real samples Si dangling bonds may be present. Inclusion of $\mathrm{Si}-\mathrm{Si}$ bonds leads to stronger absorption and, therefore, to higher calculated $k$ values.

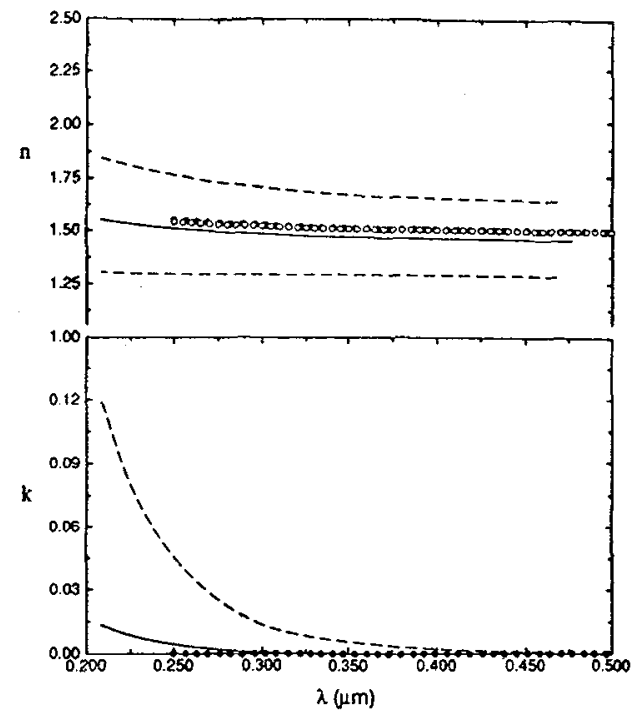

Fig. 8 Comparison between calculated (lines) and experimental (circles) $n$ and $k$ spectra for sample 1 .

The IR transmission spectra of silicon oxynitride and nitride show absorption bands related to hydrogen impurities; in particular the most intense ones at about 2200 and $3350 \mathrm{~cm}^{-1}$ are attributed to Si-H and N-H stretching modes, respectively. The spectral position of these two bands shifts to higher wave number with increasing oxygen content in the sample, as illustrated in Fig. 9. This trend can be explained very well considering the total electronegativity of the nearest neighbors of $\mathrm{Si}-\mathrm{H}$ and $\mathrm{N}-\mathrm{H}$ bonds; $[25,38]$ in oxygen-rich films it is higher than in nitrogen-rich ones, therefore the frequency of the stretching mode is also higher. The area of these absorption bands permits a quantitative evaluation of the two types of bonds, as illustrated in Sec. 2. For the silicon oxynitride films of Table IV Si-H concentration ranges from 0.6 to $2.4 \times 10^{21} \mathrm{~cm}^{-3}$ and $\mathrm{N}-\mathrm{H}$ concentration from 2.2 to $18 \times 10^{21} \mathrm{~cm}^{-3}$ going from sample 1 to 6 . Nitride samples 7 and 8 show a strong difference in the hydrogen distribution in the two bonding states. Sample 7 , deposited to obtain a good UV transparency, contains $2.2 \times 10^{21} \mathrm{~cm}^{-3} \mathrm{Si}-\mathrm{H}$ bonds and $19 \times 10^{21}$ $\mathrm{cm}^{-3} \mathrm{~N}-\mathrm{H}$ bonds, while the standard silicon nitride used in integrated circuit manufacturing, i.e. sample 8 , contains $11.3 \times 10^{21} \mathrm{~cm}^{-3} \mathrm{Si}-\mathrm{H}$ bonds and $5 \times 10^{21} \mathrm{~cm}^{-3} \mathrm{~N}-\mathrm{H}$ bonds. These findings may suggest that a correlation between hydrogen bonding state and transmission properties of the film exists, but this conclusion is not supported by all experimental data and the question remains still unsolved.

In the low wave number range the typical absorption bands related to $\mathrm{Si}-\mathrm{O}$ and $\mathrm{Si}-\mathrm{N}$ bonds are detectable. For the samples from 1 to 8 a continuous shift of the spectral position of the main absorption band is observed, from $1046 \mathrm{~cm}^{-1}$ for sample 1 to $827 \mathrm{~cm}^{-1}$ for sample 8 , compared with about $1080 \mathrm{~cm}^{-1}$ for $\mathrm{SiO}_{2}$ and about $830 \mathrm{~cm}^{-1}$ for $\mathrm{Si}_{3} \mathrm{~N}_{4}$ reported in the literature. Figure 10 shows the spectra of the as-deposited samples in the range from 1600 to $400 \mathrm{~cm}^{-1}$. The main peak, corresponding to $\mathrm{Si}-\mathrm{O}$ stretching in oxide-like samples and to $\mathrm{Si}-\mathrm{N}$ stretching in nitride-like ones, shifts to lower wave numbers as the sample composition changes from $\mathrm{SiO}_{2}$ to $\mathrm{Si}_{3} \mathrm{~N}_{4}$. This trend has to be related to the different average atomic environment of the $\mathrm{Si}-\mathrm{O}$ or $\mathrm{Si}-\mathrm{N}$ bonds in the different samples, i.e. to the different total electronegativity of their neighbors. Moreover, this behavior suggests that the optical response is due to O-Si-N groups typical of oxynitride and not to $\mathrm{Si}-\mathrm{O}$ 
and $\mathrm{Si}-\mathrm{N}$ bonds, which would give rise to two separate peaks at about the oxide and nitride wave numbers. Showing only one absorption band, the spectra of Fig. 10 suggest the conclusion that the PECVD films studied are homogeneous alloys and not two-phase compounds. $[11,25]$ Indeed, this question is still open[22] and evidence of phase separation is reported in samples deposited by different techniques. $[39,40]$

In the spectra of Fig. 10 the absorption bands due to $\mathrm{Si}-\mathrm{O}$-Si bending and rocking modes (at about 810 and $450 \mathrm{~cm}^{-1}$, respectively) are also present, with an intensity decreasing from the spectrum of sample 1 to that of sample 8 , i.e. with the change in sample composition.

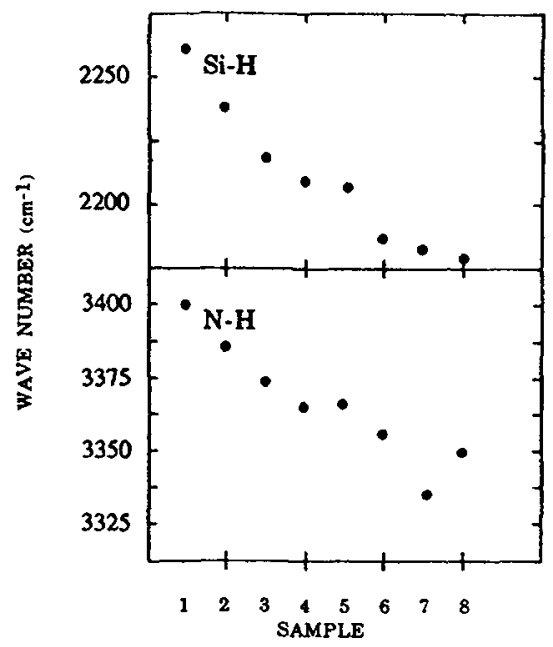

Fig. 9 Spectral position of the $\mathrm{Si}-\mathrm{H}$ and $\mathrm{N}-\mathrm{H}$ absorption bands for the different silicon oxynitride and nitride samples.

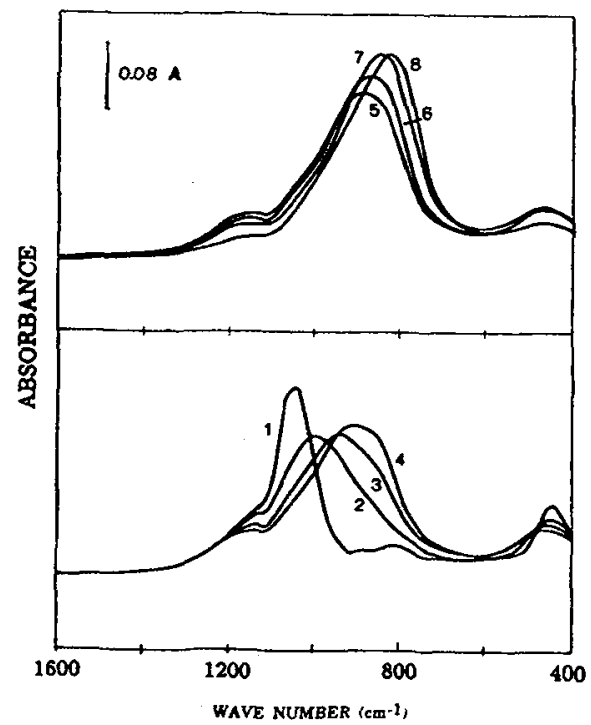

Fig. 10 Absorbance spectra of as-deposited silicon oxynitride and nitride samples. 


\section{CONCLUSIONS}

The main optical properties of several CVD dielectric films used in microelectronic device manufacturing are reviewed. Characterization in both the UV-vis and IR spectral ranges can provide information regarding the film structure, composition, and impurity content. The IR study of undoped oxides, usually employed as sidewall spacer, diffusion barrier, or intermetal and final passivation layers, permits the determination of the stoichiometry and structural order of the films with respect to a standard (usually thermal $\mathrm{SiO}_{2}$ ). Doped oxides, employed in microelectronics as intermediate and final passivation layers, are characterized according to dopant and impurity content. Analyzing silicon oxynitride and nitride films, used as final passivation layers, showed the validity of ellipsometric characterization in the UV-vis range. Atomic bonding can be closely related to the complex dielectric function of the films, as well as to the characteristic IR absorption bands. Finally, for all films, IR analysis permits the effect of annealing to be studied and the hydrogen content in the possible different bonding states to be quantified.

Here, optical techniques have been demonstrated to provide a wide characterization of CVD dielectric films and can therefore be considered as very good analytical methods to be used in the future for in situ monitoring of the CVD deposition process.

\section{Acknowledgments}

The authors would like to gratefully thank G. Ottaviani for the compositional analysis of the silicon oxynitride samples. 


\section{References}

[1] Patrick W.J., Schwartz G.C., Chapple-Sokol J.D., Carruthers R., and Olsen K., J. Electrochem. Soc. 139 (1992) 2604.

[2] Yoshimaru M., Matsuhasi H., Ajioka T., and Matsui H., "Moisture resistance of borophosphosilicate glass", 25th International IEEE Reliability Physics Conference, San Diego 7-9 April 1987 (IEEE, New York, 1987) pp. 22-27.

[3] Fujimo K., Nishimoto Y., Tokumasu N., and Maeda K., J. Electrochem. Soc. 138 (1991) 3019.

[4] Tauc J., Optical Properties of Solids, F. Abelès Ed. (North-Holland, Amsterdam, 1971) p. 277.

[5] see, for example: Wooten F., Optical Properties of Solids (Academic, New York, 1972).

[6] Aspnes D.E., Handbook of Optical Constants of Solids, D.W. Palik Ed. (Academic, Orlando, 1985) p. 89.

[7] Bruggeman D.A.G., Ann. Phys. (Leipzig) 24 (1935) 636.

[8] Tatian B., Appl. Optics 23 (1984) 4477.

[9] Forohui A.R. and Bloomer I., Phys. Rev. B 34 (1986) 7018.

[10] Pliskin W.A., J. Vac. Sci. Technol. 14 (1977) 1064.

[11] Denisse C.M.M., Troost K.Z., Oude Elferink J.B., Habraken F.H.P.M., and Van der Weg W.F., J. Appl. Phys. 60 (1986) 2536.

[12] Lanford W.A. and Rand M.J., J. Appl. Phys. 49 (1978) 2473.

[13] Watanabe H., Katoh K., and Yasui M., Thin Solid Films 106 (1983) 263.

[14] Adams A.C., Solid Sta.te Technology, April (1983) 135.

[15] Herrick N.J., Internal Reflection Spectroscopy (John Wiley \& Sons, New York, 1979).

[16] Brendel R., Appl. Phys. A 50 (1990) 587.

[17] Borghesi A. and Sassella A., Phys. Rev. B 50 (1994) 17756.

[18] Röseler A., Infrared Spectroscopic Ellipsometry (Akademie-Verlag, Berlin, 1990).

[19] Rojas S., Modelli A., Wu W.S., Borghesi A., and Pivac B., J. Vac. Sci. Technol. B 8 (1990) 1177.

[20] Rojas S., Zanotti L., Borghesi A., Sassella A., and Pignatel G.U., J. Vac. Sci. Technol. B 11 (1993) 2081.

[21] Rojas S., Gomarasca R., Zanotti L., Borghesi A., Sassella A., Ottaviani G., Moro L., and Lazzeri P., J. Vac. Sci. Technol. B 10 (1992) 633.

[22] Habraken F.H.P.M. and Kuiper A.E.T., Mat. Sci. Eng. R12 (1994) 123 and Refs, therein.

[23] Borghesi A., Sassella A, and Rojas S., Thin Solid Films 233 (1993) 227.

[24] Borghesi A., Bellandi E., Guizzetti G., Sassella A., Rojas S., and Zanotti L., Appl. Phys. A 56 (1993) 147.

[25] Sassella A., Borghesi A., Rojas S., and Zanotti L., "Chemical-bond analysis of hydrogen-rich silicon oxynitride", 9th International Conference on Fourier Transform Spectroscopy, Calgary 23-27 August 1993, J.E. Bertie and H. Wieser Ed. (SPIE 2089, Washington, 1994) pp. 398399.

[26] Sassella A., Lucarno P., Borghesi A., Corni F., Rojas S., and Zanotti L., J. Non-Cryst. Solids (1995) in press. 
[27] Hubner K., Phys. Status Solidi (a) 61 (1980) 665.

[28] Nguyen V.S. and Pan P.H., Appl. Phys. Lett. 45 (1984) 134.

[29] Nguyen V.S., Burton S., and Pan P., J. Electrochem. Soc. 131 (1984) 2348.

[30] Waytena G.L., J. Electrochem. Soc. 140 (1993) 766.

[31] Ordejón P. and Ynduráin F., J. Non-Cryst. Solids 137/138 (1991) 891.

[32] Ance C., De Chella F., Ferraton J.P., Lévèque G., Ordejón P., and Ynduráin F., Appl. Phys. Lett. 60 (1992) 1399.

[33] Ordejón P. and Ynduráin F., Phys. Rev. B 43 (1991) 4552.

[34] Cros Y., Rostaing J.C., Peisner J., Lévèque G., and Ance C., J. Appl. Phys. 62 (1987) 4538.

[35] Sassella A., Phys. Rev. B 48 (1993) 14208.

[36] Aspnes D.E. and Theeten J.B., J. Appl. Phys. 50 (1979) 4928.

[37] Yin Z. and Smith F.W., Phys. Rev. B 42 (1990) 3658; 3666.

[38] Lucovsky G., J. Vac. Sci. Technol. 16 (1979) 1225.

[39] Taft E.A., J. Electrochem. Soc. 118 (1971) 1341.

[40] Schalch D., Sharman A., and Wolfrat R., Thin Solid Films 155 (1987) 301. 